\title{
Active LR Integrator Circuit with Ferrite Core
}

\author{
P. GAZDA ${ }^{a * *}$, M. NOWICKI ${ }^{a}$ AND M. KACHNiARZ ${ }^{b}$ \\ ${ }^{a}$ Institute of Metrology and Biomedical Engineering, Warsaw University of Technology, \\ A. Boboli 8, 02-525 Warsaw, Poland \\ ${ }^{b}$ Industrial Research Institute for Automation and Measurements PIAP, \\ Al. Jerozolimskie 202, 02-486 Warsaw, Poland
}

\begin{abstract}
The paper presents the idea of active LR integrator circuit based on ferrite core. The LR topology, in contrast to contemporary RC, allow for drift-free operation of the integrator. Presented circuit is intended as main component of continuous operation fluxmeters and magnetoelastic transducers, especially working with low frequency signals. Critical component for proper frequency range and low signal distortion is the core material, which should allow for close-to-ideal inductance in the circuit. Presented simulation, measurement results, and total harmonic distortion analysis show that the proposed circuit works correctly.
\end{abstract}

DOI: 10.12693/APhysPolA.133.1041

PACS/topics: 41.20.Gz, 85.70.Ay, 85.70.Ge

\section{Introduction}

The measurement of magnetic quantities, such as hysteresis loop of ferrites [1] and novel amorphous alloys [2], involves integration of voltage signals. Nowadays, mostly active RC integrators are used [3]. However, in applications such as very low frequency measurements, or continuous measurements [4] the RC topology is problematic because of the inherent output drift of the circuit. In this paper, the active LR integrating circuit is presented, based on the high permeability and low coercivity of $3 \mathrm{e} 6$ $\mathrm{Mn}-\mathrm{Zn}$ ferrite material core of the inductive component. The integration is based on accumulation of magnetic flux in the ferrite core, not the electric charge as in the RC type. The presented circuit allows for drift-free operation, as due to inductance non-ideality it has no response for the dc component of the input signal. It is thus possible to obtain continuous integration of the applied signal, such as measurement of the magnetic hysteresis loop, or magnetoelastic force transducers [5].

\section{Outline of the LR integrator}

In the developed integrator circuit contemporary (and most popular) RC topology is substituted with LR one. The reaction of such system for input signal should be the same as reaction of the RC system. Moreover, replacing energy storing capacitor with a resistor in negative feedback loop should provide drift-free operation.

Obtaining the proper integration operation for LR systems is hard to achieve. The occurrence of series resistance $R_{L}$ of wire from which the coil is manufactured, which is always present for non-superconducting coils, changes the nature of the circuit to inertial first-order system. However, because the operation of such system is identical for the initial period as the operation of the

*corresponding author; e-mail: p.gazda@mchtr.pw.edu.pl integrating system, the desired properties can be provided. For this purpose, the frequency of the analysis signal should be at least 10 times greater than a natural frequency $\omega_{0}$ of the system, which can be calculated from the following formula:

$$
\omega_{0}=R_{L} / L \text {. }
$$

For some magnetic measurements, especially in case of large inertia of magnetic domains movement, or in order to reduce eddy current losses, working frequencies are low, in the $0.01 \mathrm{~Hz} \div 10 \mathrm{~Hz}$ range. The lower limit of the LR operating frequency is given by Eq. (1) times 10. In our previous work [6] we show that coils with air core do not allow to reduce this frequency below $100 \mathrm{~Hz}$.

Decrease of the lower limit of working frequencies of the system in accordance with Eq. (1) is associated with the limitation of $R_{L}$ to $L$ ratio. To reduce $R_{L}$, coils of heavy gauge wire should be used, but the best effect of reducing the coefficient would be to use a core with high permeability to increase the $L$. For such parameters, modern ferrite cores, such as the $3 \mathrm{e} 6 \mathrm{Mn}-\mathrm{Zn}$ core from Ferroxcube, with a relative permeability of 25280 for a $10 \mathrm{kHz}$ test frequency, are necessary. The advantage of such cores over cores made of nanocrystalline strips whose permeability can be several times greater, is the greater value of the field at which the core is saturated. This means that more current can flow through the coil before it saturates and distorts the signal. This is particularly important at low frequencies when the impedance of the coil is small which allows the flow of considerable current.

\section{SPICE simulation}

Figure 1 presents the circuit design in open source SPICE Program - LTSpice. To isolate integrating block from input or output load, voltage followers were applied in the circuit. Without it load can have influence on integrating block, changing working parameters.

Most significant in the simulation was to take account of core hysteresis and the phenomenon of core saturation 


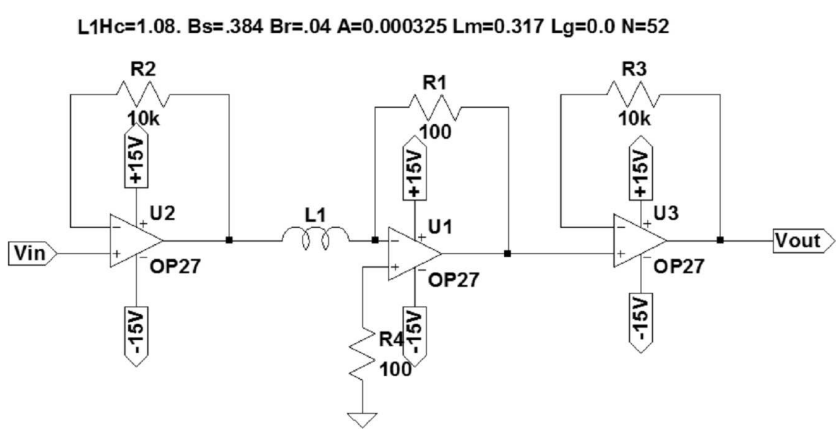

Fig. 1. Model of the LR integrator circuit design in SPICE software.

in particular, because the saturated coil acts like an air coil which significantly changes the parameters of the system. The model proposed in [7] and developed in [8] is implemented in the environment. In this solution the hysteresis loop is described by the parameters: remnant flux density $B_{r}$, saturation flux density $B_{s}$ and coercive force $H_{c}$, and the upper and lower branches of the hysteresis loop are given by Eqs. (2), (3):

$$
\begin{aligned}
& B_{u p}(H)=B_{s} \frac{H+H_{c}}{\left|H+H_{c}\right|+H_{c}\left(\frac{B_{s}}{B_{r}}-1\right)}+\mu_{0} H \\
& B_{l o}(H)=B_{s} \frac{H-H_{c}}{\left|H-H_{c}\right|+H_{c}\left(\frac{B_{s}}{B_{r}}-1\right)}+\mu_{0} H .
\end{aligned}
$$

The required core parameters were measured using hysteresis graph [1]. Geometrical parameters of the coil are also required to determine the magnetic field $H$ : the length of the magnetic path $L_{m}$, the cross-sectional area of the core $A$, and the number of turns $N$. Figure 2 presents operation of the system for step function input for $f=1.5 \mathrm{~Hz}$. The output is a triangle, just as expected.

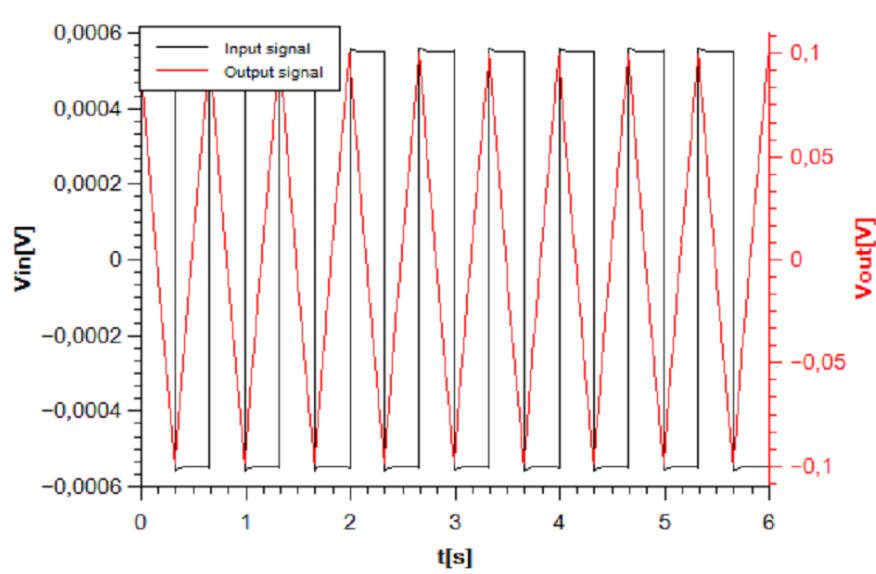

Fig. 2. Output of the simulated system for step function, $f=1.5 \mathrm{~Hz}$.

Figure 3 presents the Bode diagram for the designed circuit. Characteristic for the integrator system is a $20 \mathrm{~dB}$ gain drop per decade and phase shift equal to 90 degrees. It can be seen that for frequencies above $1.5 \mathrm{~Hz}$ the system achieves the proper gain dependence.
The phase shift difference from the assumed 90 degrees, for a frequency of $1.5 \mathrm{~Hz}$ to $40 \mathrm{kHz}$ is less than 2 degrees. Generally, in the operating range of the system, the gain $k_{u}$ and phase shift $\varphi$ can be determined from formulas

$$
\begin{aligned}
& k_{u}(\omega)=\frac{V_{\text {out }}}{V_{\text {in }}}=-\frac{Z_{2}}{Z_{1}}=\frac{R}{\omega L+R_{L}}, \\
& \varphi(\omega)=180^{\circ}-\arctan \frac{\omega}{\omega_{0}}=180^{\circ}-\arctan \frac{\omega L}{R_{L}} .
\end{aligned}
$$

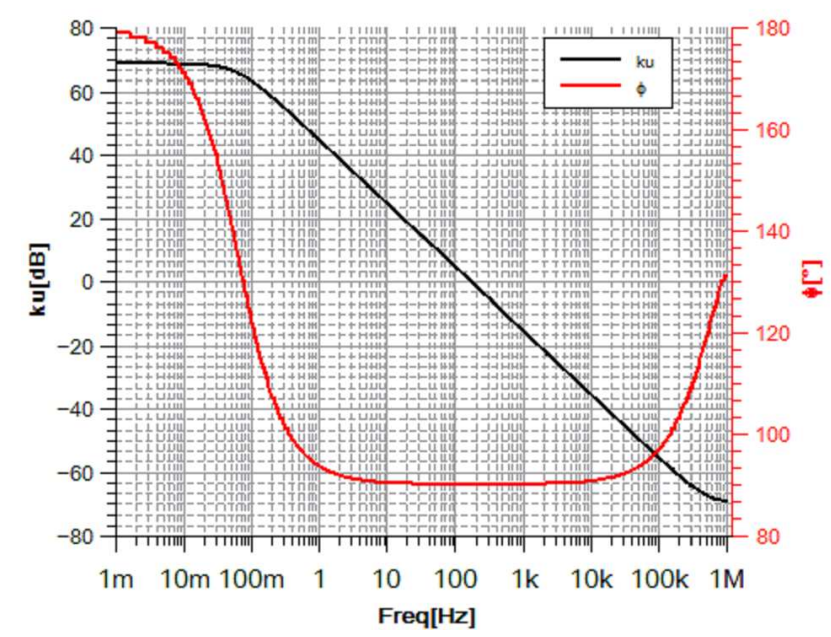

Fig. 3. Bode diagram of the designed LR integrator circuit.

\section{Experimental results}

For the tests, the prototype circuit was made according to the diagram presented in Fig. 1. First of all, the system was tested as triangle generator. According to the theoretical dependence of integration operation, step input gives triangle output. System works properly for tested frequencies of $1 \mathrm{kHz}, 100 \mathrm{~Hz}, 10 \mathrm{~Hz}$, and $1.5 \mathrm{~Hz}$ for which acquired signal is presented in Fig. 4. This frequency is the lowest value for which system integrates properly. The resulting waveforms are consistent with simulation predictions.

Next, the system was tested as a fluxmeter. As it is presented in Fig. 5 magnetizing signal was sinusoidal. Figure 5 shows also proper operation of the system. During the measurement we noticed that decrease of working frequency causes increase of current which can result in saturation of a coil what was mentioned before. System was also tested for long term integrating action. For frequency of $5 \mathrm{~Hz}$ commercial fluxmeter have a $0.5 \mathrm{~V}$ drift per minute (without additional drift compensation) or $0.166 \mathrm{mV}$ per minute (in digital drift track mode). For the same conditions, presented system has $0.012 \mathrm{mV}$ per minute, which is presented in Fig. 6.

Final part of investigation of developed solution was to measure the level of total harmonic distortion (THD). The system was tested at a frequency of $20 \mathrm{~Hz}$, which 


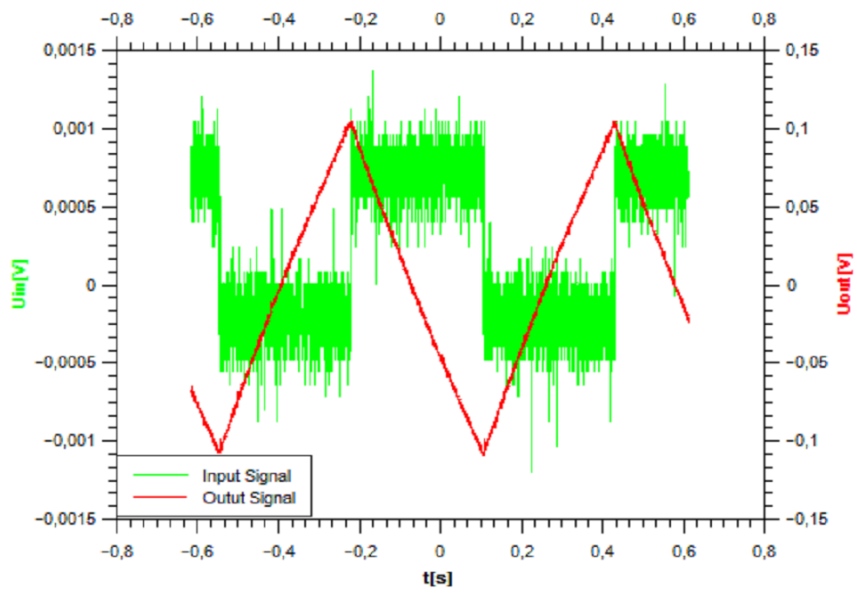

Fig. 4. Acquired signals for the prototype system for step function input, $f=1.5 \mathrm{~Hz}$.

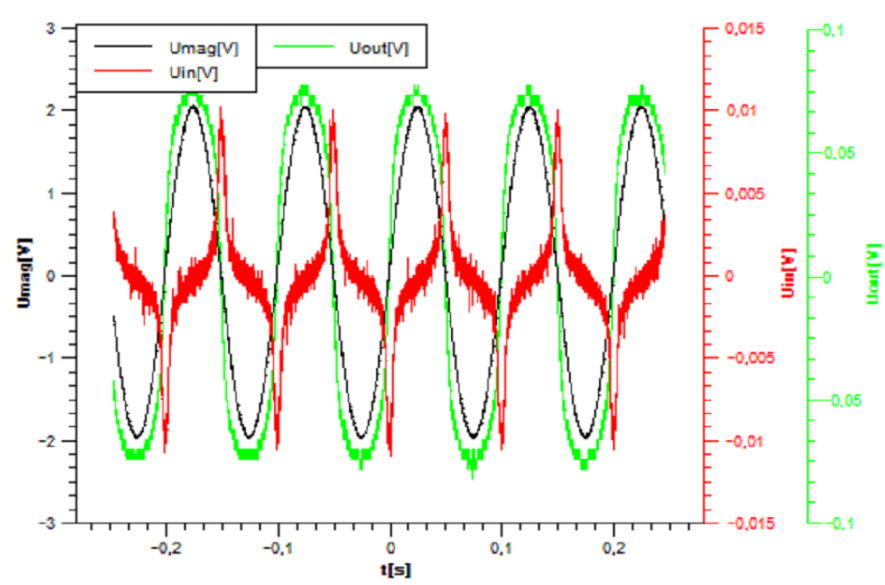

Fig. 5. Output of the prototype system for signal induced in measurement coil for $f=10 \mathrm{~Hz}$.

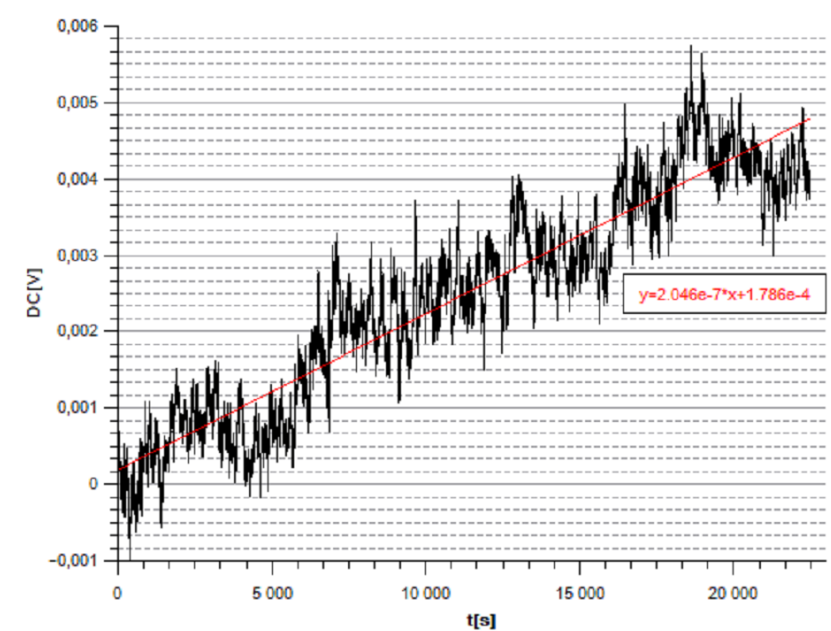

Fig. 6. Measured value of dc offset of output signal for long-term measurements, $f=5 \mathrm{~Hz}$. is the value of the lower measuring range of PMZ-12 automatic distortion meter, up to a frequency of $500 \mathrm{~Hz}$. Figure 7 presents the measured dependency of THD coefficient on frequency. It can be seen that for frequencies above $30 \mathrm{~Hz}$ THD falls below $1 \%$ and for frequencies above $130 \mathrm{~Hz}$ - below $0.1 \%$. This proves that the system does not introduce considerable nonlinear distortion and proves its correct operation.

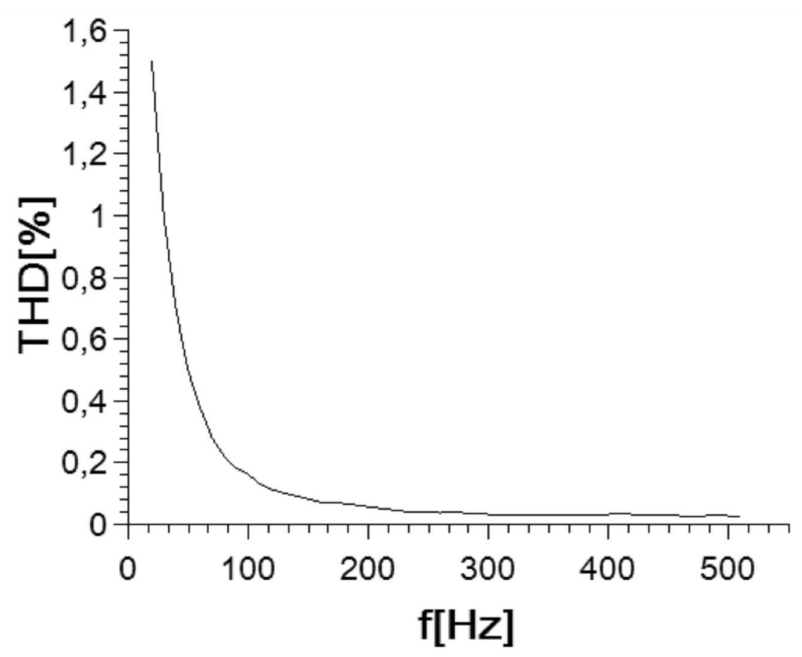

Fig. 7. THD level of the developed circuit.

\section{Conclusions}

In the presented paper, we have shown the correctness of the integrator operation of proposed circuit. The system can operate in the range of $1.5 \mathrm{~Hz}$ to $40 \mathrm{kHz}$ (but for frequency higher than $5 \mathrm{kHz}$ amplification is required). This type of integrator circuit can be used to develop the drift-free fluxmeter for investigation of ferromagnetic hysteresis phenomenon in soft magnetic materials, such as ferrites and amorphous alloys. Moreover, the main advantage of proposed system lies in its innate ability for continuous, drift-free operation, which may be useful in novel NDT methods [9], as well as magnetoelastic sensors transducers.

\section{Acknowledgments}

This work was partially supported by the statutory founds of Institute of Metrology and Biomedical Engineering, Warsaw University of Technology (Poland).

\section{References}

[1] T. Charubin, M. Urbański, M. Nowicki, in: Recent Advances in Systems, Control and Information Technology, Eds. R. Szewczyk, M. Kaliczyńska, Springer, Cham 2016, p. 593.

[2] M. Nowicki, P. Švec, D. Jackiewicz, R. Szewczyk, in: Progress in Automation, Robotics and Measuring Techniques, Eds. R. Szewczyk, C. Zieliński, M. Kaliczyńska, Springer, Cham 2015, p. 197. 
[3] M. Urbański, T. Charubin, P. Rozum, M. Nowicki, R. Szewczyk, in: Challenges in Automation, Robotics and Measurement Techniques, Eds. R. Szewczyk, C. Zieliński, M. Kaliczyńska, Springer, Cham 2016, p. 817.

[4] D. Jackiewicz, R. Szewczyk, M. Kachniarz, Acta Phys. Pol. A 131, 1189 (2017)

[5] J. Salach, A. Bieńkowski, R. Szewczyk, J. Magn. Magn. Mater. 316, E607 (2007).
[6] P. Gazda, M. Nowicki, M. Kachniarz, M. Szudarek, R. Szewczyk, in: Automation 2017 Innovations in Automation Robotics and Measurement Techniques, Eds. R. Szewczyk, C. Zieliński, M. Kaliczyńska, Springer, Cham 2017, p. 519 .

[7] J.H. Chan, A. Vladimirescu, X.C. Gao, P. Liebmann, J. Valainis, IEEE Trans. Comput.-Aid. Des. Integrat. Circ. Syst. 10, 476 (1991).

[8] M.T. Engelhardt, 2009, U.S. Patent No. US 7502723 B1, Washington, DC, U.S. Patent and Trademark Office.

[9] D. Jackiewicz, R. Szewczyk, A. Bieńkowski, J. Electr. Eng. - Elektrotechnicky Casopis 66, 178 (2015). 